\title{
Is Openness Good for Stagnation?
}

\author{
Wataru Johdo \\ Tezukayama University
}

\begin{abstract}
Using a symmetric multi-country model that allows for the possibility of stagnation, this paper analyzes the effects of openness on effective demand. A regime shift from autarky to free trade boosts the value of consumption utility by expanding the range of consumption goods available to people in every country. However, under stagnation, the rise in value of consumption utility lowers the time preference rate through a decline in the inflation rate, while not affecting the liquidity premium that represents the desire to hold money. Therefore, openness causes realized consumption to decrease and saving to increase. Consequently, effective demand decreases.
\end{abstract}

- JEL classification: E24, F15, L11, L13

- Keywords: Autarky, Openness, Effective Demand, Stagnation

\section{Introduction}

An enormous number of studies in the international trade literature examine the welfare gain from openness. In the familiar Ricardian model, where there are two countries, two types of goods, and a single production input, openness (or free trade) increases welfare of two trading economies because there is international comparative advantage due to technological differences between them. More recently, in the endogenous growth literature, where technological knowledge contributed by local research and development is a global public good, openness

\footnotetext{
*Corresponding address: Wataru Johdo, Department of Economics, Tezukayama University, 7-1-1, Tezukayama, Nara 631-8501, Japan, Tel: +81-742-48-9380; Fax: +81-742-46-4994, E-mail: johdo@ tezukayama-u.ac.jp

@ 2008 -Center for International Economics, Sejong Institution, All Rights Reserved.
} 
boosts the rate of output growth and welfare of two trading countries, because knowledge spillovers augment R\&D productivity worldwide. ${ }^{1}$ Important contributions to this literature include Young (1991), Rivera-Batiz and Romer (1991a, b), Grossman and Helpman (1991), Baldwin and Forslid (1998, 1999, 2000) and Peretto (2003). ${ }^{2}$ However, the models proposed in the literature are based on the assumption that demand is always met with supply in both labor and goods markets. ${ }^{3}$ Thus, the question remains as to whether openness increases effective demand when stagnation occurs.

In contrast to the international trade literature described above, Ono (2001) investigated the possible existence of stagnation equilibrium. In a reinterpretation of Chapter 17 of Keynes's General Theory, which is concerned with shortage of effective demand, he showed that stagnation may occur when two non-neoclassical assumptions are fulfilled. Introducing money to the utility function, these are insatiable liquidity preference, $\lim v^{\prime}(m)=\beta$ for $m \rightarrow \infty$, and sluggish price adjustments. It was found that "Keynes's rule" - an equilibrium condition —may not be fulfilled unless consumption, $c$, is less than output, $y$, i.e., "effective demand shortage". This main result is seen from Keynes's rule that $\rho+\dot{P} / P=R=v^{\prime}(m) /$ $u^{\prime}(c)$, where $r+\dot{P} / P$ is the rate of time preference in terms of money, $\dot{P} / P$ is the instantaneous rate of inflation that is zero (negative) when $c=y(c<y), R$ is the nominal rate of return to equities, and $v^{\prime}(m) / u^{\prime \prime}(c)$ is the liquidity premium of money. ${ }^{4}$ The lower bound of the liquidity premium, a liquidity trap, therefore equals $\beta / u^{\prime}(c)$. It may be the case that $\rho<R=\beta / u^{\prime}(y)$ requires that $c<y$, implying that "effective demand shortage" with deflation (i.e., stagnation) occurs. Hence Keynes's rule cannot be fulfilled for $c=y$ due to $u^{\prime \prime}(c)<0$. Using such a model, Ono considered the effective demand effects of various demand stimulus policies, such as additional fiscal spending and monetary expansion. However, Ono (2001) ignored the impacts of openness on effective demand, because he employed a

\footnotetext{
${ }^{1}$ Lee et al. (2004) attempt to provide a justification for the relationship between openness and growth empirically.

${ }^{2}$ Grossman and Helpman (1995) present a survey of the relationship between international trade and endogenous growth in more detail.

${ }^{3}$ In this paper, we define stagnation as a state where effective demand shortage and involuntary unemployment co-exist, resulting in a persistent deflation.

${ }^{4}$ Note that all rates of return in "Keynes's rule" are measured in monetary terms. If we rewrite the Keynes's rule in real terms, we obtain $\rho=r=v^{\prime}(m) / u^{\prime}(c)-\dot{P} / P$, where $r=R-\dot{P} / P$ is the real interest rate.
} 
closed economy setting.

How does openness affect the effective demand in each country under stagnation? This paper takes the idea of stagnation in Ono (2001) and combines it with the monopolistic trade model of Peretto (2003) to account for the impact of openness on effective demand of each country in a situation where all countries are in a state of stagnation. This combination implies that the production side of the model is more complicated than in the Ono model. In Ono's (2001) model, there is one type of commodity with output $y$ that is produced cost-free by firms (such as mineral water or fruits from a pear tree) in a closed economy setting. Adopting the production side of Peretto's (2003) model implies many differentiated tradable commodities produced with labor as the production factor, as well as firms that possess market power. Furthermore, to keep the analysis tractable, we assume that all countries are symmetrical. Using the above symmetric multi-country model, we generate predictions about the effect of openness on effective demand under stagnation. Specifically, we consider the impact of the movement from autarky to free trade and reach the following relationship between openness and effective demand. The regime shift from autarky to free trade expands the range of consumption goods available to people in every country and thereby increases the value of people's consumption utility function. This implies that people can enjoy higher utility without increasing expenditure for consumption. However, under stagnation, where expenditure for consumption has reached an upper bound, the rise in efficiency of consumption utility lowers the time preference rate of Keynes's rule through a decline in the inflation rate, while not affecting the liquidity premium that represents the desire to hold money. Therefore, openness causes realized consumption to decrease and saving to increase in all countries. Consequently, effective demand decreases and stagnation worsens.

The remainder of this paper is organized as follows. In the next section, we specify preferences and technologies and describe optimal behavior of individual agents. Equilibrium conditions are presented in section III. Conditions for the steady state with stagnation are developed in section IV. The effect of openness is studied in section V. Section VI concludes.

\section{The Model}

There are $x$ countries in this world economy. Each country has a fixed population, $h$, of households, each endowed with one unit of labor. All households 
are assumed to have identical preferences and all firms have identical technologies. A typical household in each country not only has preferences over a continuum of differentiated products but also has a preference for real money balances. In the household's decision, each household determines the composition of differentiated goods under a given level of nominal expenditure in the first stage, and then determines real consumption expenditure and real money holdings over time in the second stage. On the production side, global oligopolists create blueprints for new products by investing in $\mathrm{R} \& \mathrm{D}$ and, simultaneously, produce differentiated products invented previously. They engage in worldwide Bertrand price competition, in which they select a price so as to maximize profits, subject to their demand schedules. This guarantees that supply equals demand in each goods market.

\section{A. Households}

A typical consumer in country $k$ maximizes the following lifetime utility:

$$
\begin{gathered}
U_{k}=\int_{0}^{\infty}\left[\log d_{k}+v\left(m_{k}\right)\right] \exp (-\rho t) d t, \\
v^{\prime}\left(m_{k}\right)>0, v^{\prime \prime}\left(m_{k}\right)<0, v^{\prime}(\infty)=\beta>0,
\end{gathered}
$$

where the constant parameters $\rho$ and $\beta$ are assumed to be identical for all countries, $d_{k}$ denotes a consumption index defined below, $v\left(m_{k}\right)$ denotes the liquidity preference of real money balances $m_{k}$. In (2), $v^{\prime}(\infty)=\beta>0$ implies that there is no saturation point in the individual's liquidity preference even if $m_{k}$ keeps increasing. ${ }^{5}$ The real-flow budget constraint of a typical household in country $k$ is

$$
\dot{a}_{k}=r_{k} a_{k}+w_{k} l_{k}^{s}-d_{k}-R_{k} m_{k}
$$

where $a_{k}$ ( $\left.\equiv A_{k} / \bar{P}_{k}\right)$ denotes the real value of total asset holdings consisting of equities $b_{k}$ and real balances, or $a_{k}=b_{k}+m_{k}$, where $A_{k}$ denotes the total nominal stock of assets and $\bar{P}_{k}$ denotes the price level. The real wage rate is denoted by $w_{k}$ ( $\left.\equiv W_{k} / \bar{P}_{k}\right)$, where $W_{k}$ is the nominal wage rate and $l_{k}^{s}$ is labor supply, and $R_{k}\left(=r_{k}\right.$

\footnotetext{
${ }^{5}$ Ono et al. (2004) attempted to provide a justification for the existence of insatiable liquidity preference by testing for it empirically in Japan using two data sets, prefectural and individual. In their empirical investigation, they used two different econometric methods-parametric and nonparametric-and showed that insatiable liquidity preference is significantly positive at standard significance levels.
} 
$\left.+\dot{\bar{P}}_{k} / \bar{P}_{k}\right)$ is the nominal market rate of return where $\dot{\bar{P}}_{k} / \bar{P}_{k}$ is the instantaneous rate of inflation and $r_{k}$ is the market real interest rate. ${ }^{6}$ Here we assume that the households supply their own labor that is determined according to $l_{k}^{s}=\min \left[1,\left(n_{k} l_{k}\right.\right.$ $+1) / h$, where $n_{k}$ is the number of firms in country $k, l_{k}$ is labor input of a typical firm in country $k$, and $\imath$ is labor demand required by R\&D activities, and $\left(n_{k} l_{k}+\mathrm{l}\right) /$ $h$ is the labor demand for households per capita in country $k$. This implies that realized labor supply is determined on the short side as either an inelastic labor supply, or as the actual labor demand by firms. Hence labor supply is demand-determined.

In the first stage, we consider the composition of a given level of nominal spending $E_{k}$ at each instant to maximize $d_{k}$. Let $c_{j k}$ be the consumption of good $j$ produced in country $k$. Then the consumption index aggregating across the differentiated varieties and among countries is given by

$$
d_{k}=\left[\sum_{j=1}^{n_{k}} c_{j k}^{(\sigma-1) / \sigma}+\sum_{s \neq k}^{x} \sum_{j=1}^{n_{s}} c_{j s}^{(\sigma-1) / \sigma}\right]^{\sigma /(\sigma-1)}, \sigma>1,
$$

where $n_{k}$ denotes the set of products in country $k$ because there is a one-to-one correspondence between firms and varieties. The typical household in country $k$ maximizes (4) subject to

$$
E_{k}=\sum_{j=1}^{n_{k}} P_{j k} c_{j k}+\sum_{s \neq k}^{x} \sum_{j=1}^{n_{s}} P_{j s} c_{j s},
$$

where $c_{j s}$ is consumption of good $j$ imported from country $s, P_{j k}$ is the price of good $j$ produced in country $k$, and $P_{j s}$ is the price of good $j$ imported from country $s$. The price index of consumption goods in country $k$ is

$$
\bar{P}_{k}=\left[\sum_{j=1}^{n_{k}} P_{j k}^{1-\sigma}+\sum_{s \neq k}^{x} \sum_{j=1}^{n_{s}} P_{j s}^{1-\sigma}\right]^{1 /(1-\sigma)}
$$

Solving the above optimization problem, one finds that a typical household demands good $j$ according to the following schedule:

$$
\begin{aligned}
& c_{j k}{ }^{D}=E_{k}\left(P_{j k}^{-\sigma} / \bar{P}_{k}^{1-\sigma}\right), \\
& c_{j s}^{F}=E_{k}\left(P_{j s}^{-\sigma} / \bar{P}_{k}^{1-\sigma}\right),
\end{aligned}
$$

\footnotetext{
${ }^{6}$ Lower case letters denote real variables and capital letters denote nominal variables. Thus, the nominal budget equation is represented by $\dot{A}_{k}=R_{k} B_{k}+W_{k} l_{k}^{s}-\bar{P}_{k} d_{k}$ where $B_{k}$ denotes the nominal value of equities.
} 
where $c_{j k}{ }^{D}$ denotes the demand for good $j$ when good $j$ is produced domestically, and $c_{j s}{ }^{F}$ denotes the demand for good $j$ when good $j$ is imported. Aggregating the demands across all households and equating the resulting equation to the output of good $j$ produced in country $k, y_{j k}$, yields the following market clearing condition for any good $j$ :

$$
y_{j k}=h E_{k}\left(P_{j k}^{-\sigma} / \bar{P}_{k}^{1-\sigma}\right)+\sum_{s \neq k}^{x} h E_{s}\left(P_{j k}^{-\sigma} / \bar{P}_{s}^{1-\sigma}\right) .
$$

where $\bar{P}_{s}$ is the price index of consumption goods in country $s$. Furthermore, from (4), (6), (7) and (8), we obtain $d_{k}=e_{k}\left(\equiv E_{k} / \bar{P}_{k}\right)$, where $e_{k}$ represents real consumption expenditure.

In the second stage, we consider the dynamic optimization problem of a typical agent in country $k$. The Hamiltonian is given by $H=\left[\log e_{k}+v\left(m_{k}\right)\right] e^{-\rho t}+\lambda\left[r_{k} a_{\kappa}+\right.$ $\left.w_{k} l_{k}^{s}-e_{k}-R_{k} m_{k}\right]$. The first-order conditions for this problem are $\left(1 / e_{k}\right) e^{-\rho t}=\lambda$ and $-\dot{\lambda}=r_{k} \lambda, v^{\prime}\left(m_{k}\right) e^{-\rho t}=R_{k} \lambda$, and the transversality condition is $\lim _{t \rightarrow} \lambda_{t} a_{k t}=0$. From the first order conditions, we obtain

$$
\rho+\dot{e}_{k} / e_{k}+\dot{\bar{P}}_{k} / \bar{P}_{k}=R_{k}=v^{\prime}\left(m_{k}\right) e_{k}
$$

Ono (2001) called this condition 'Keynes's rule'. The left hand side of (10) shows the time preference rate in terms of money, while the right hand side represents the liquidity premium of money, which is the marginal rate of substitution between consumption and money holdings.

We now turn to the production side. Price-setting firms undertake two activitiesmanufacturing differentiated products invented previously, and investing in R\&D for creating new products. There is only one factor of production, labor. For each variety, one unit of labor is needed to produce one unit of output, $y_{j k}=l_{j k}$. This makes the marginal cost of every product equal to the nominal wage rate $W_{k}$. Given $W_{k}, \bar{P}_{k}$ and aggregate real consumption expenditure $h e_{k}$ (hereafter we shall refer to $h e_{k}$ as 'effective demand' in country $k$ ), firm $j$ faces the following profitmaximization problem:

$$
\begin{gathered}
\max _{p j} \prod_{j k}=P_{j k} y_{j k}-W_{k} l_{j k}, \\
\text { s.t. } y_{j k}=h E_{k}\left(P_{j k}^{-\sigma} / \bar{P}_{k}^{1-\sigma}\right)+\sum_{s \neq k}^{x} h E_{s}\left(P_{j k}^{-\sigma} / \bar{P}_{s}^{1-\sigma}\right),
\end{gathered}
$$


where $\Pi_{j k}$ denotes the nominal profit. Given the above problem, a price mark-up is chosen according to

$$
P_{j k}=\left[\xi_{k} /\left(\xi_{k}-1\right)\right] W_{k}
$$

where $\xi_{k} \equiv \sigma-(\sigma-1)\left(1 / x n_{k}\right)$ is the price elasticity of demand. As $W_{k}$ is given, (13) yields $P_{j k}=P_{k}, j \in\left[0, n_{k}\right]$. These relationships imply that each firm in country $k$ supplies the same quantity, i.e., $y_{j k}=y_{k}, j \in\left[0, n_{k}\right]$.

Next, we consider the stock-market valuation of profit-making firms. A noarbitrage condition in country $k$ relates equity returns to the return on a consumption loan. Thus, the no-arbitrage condition is

$$
\pi_{k} / q_{k}+\dot{q}_{k} / q_{k}=r_{k}
$$

where $q_{k}$ is the real value of equity of a firm that succeeded in creating a new blueprint in country $k$. Finally, following the model of Grossman and Helpman (1991, ch. 3), we formulate the R\&D activity. A firm that devotes 1 units of labor to $R \& D$ acquires the ability to produce new blueprints. Since the cost of developing new blueprints in country $k$ equals $\phi w_{k}$, where $\phi$ is the productivity of the R\&D technology, the smaller is $\phi$, the smaller is the R\&D cost. Furthermore, we assume that firms issue equities to finance the cost of R\&D. Since $q_{k}$ also equals the present discounted value of real profit flow, free entry into the innovative $R \& D$ implies

$$
\phi w_{k} \geq q_{k} \text { with equality whenever } \dot{n}_{k}>0 \text {. }
$$

The free entry condition (15) is compatible with corner solutions in which innovation halts, such that $\dot{n}_{k}=0$, when $\phi w_{k}=q_{k}$.

\section{Market Equilibrium Conditions}

The money markets are assumed always to clear in all countries:

$$
h m_{k}=M_{k}^{s} / \bar{P}_{k}, \forall k,
$$

where $M_{k}{ }^{s}$ represents nominal money supply in country $k$ and is assumed to be constant. ${ }^{7}$ In the labor market, generally, nominal wages take time to adjust to 
excess labor demand. Therefore, as in Ono (2001), we assume that nominal wagerate adjustment is sluggish and formulate it as the following process:

$$
\dot{W}_{k} / W_{k}=\alpha\left(\left(n_{k} l_{j k}+\phi \dot{n}_{k}\right) / h-1\right), \forall k,
$$

where $n_{k} l_{j k}$ is labor demand required by manufacturing in country $k$ and $\phi \dot{n}_{k}(=\mathfrak{l})$ is labor demand required by $R \& D$ activities. The constant exogenous parameter $\alpha$ represents the speed of nominal wage adjustment. ${ }^{8}$ From (17), the nominal wage rises or falls gradually to the extent that total labor demand $\left(n_{k} l_{j k}+\phi \dot{n}_{k}\right)$ exceeds or falls short of total labor supply $h .^{9}$

\section{Steady State with Stagnation}

To keep the analysis tractable, this paper focuses on symmetrical countries. From the symmetry assumption, we obtain the following relationship:

$$
r_{k}=r, R_{k}=R, e_{k}=e, n_{k}=n, y_{k}=y, m_{k}=m, q_{k}=q, \bar{P}_{k}=\bar{P}, P_{k}=P, W_{k}=W, \forall k .
$$

From (6) and the above symmetry assumption, the relationships, $P_{j k}=P_{k}, j \in[0$, $\left.n_{k}\right], \in$, yields $P_{j k} / \bar{P}_{k}=P_{k} / \bar{P}_{k}=n^{-1 /(1-\sigma)} x^{-1 /(1-\sigma)}$, where $P_{j k} / \bar{P}_{k}$ is the real price of product $j$ in country $k$. Then, from (12), we obtain

$$
y_{k}=y=h x^{1 /(1-\sigma)} e n^{\sigma /(1-\sigma)} .
$$

Substituting (13) and (18) into (11) yields the real profit flow $\left(\equiv \pi_{k}=\Pi_{k} / \bar{P}_{k}\right)$ as follows:

$$
\pi_{k}=\pi=[1 /(\xi-1)] w h x^{1 /(1-\sigma)} e n^{\sigma /(1-\sigma)},
$$

where $\xi \equiv \sigma-(\sigma-1)(1 / x n)$.

Here, we define stagnation as a state in which involuntary unemployment and

\footnotetext{
${ }^{7}$ Our main results are not qualitative changes, even if we relax the assumption that the nominal money supply grows at a constant rate, as is commonly assumed in monetary-theory literature. Hence, for simplicity, we assume that the nominal money supply is constant. Ono (2001) examines the effective demand effect of a changing growth rate of money supply.

${ }^{8}$ Johdo (2002), Matsuzaki (2003), and Ono (2006) also used this type of sluggish adjustment mechanism.

${ }^{9}$ Naturally, when full employment holds, that is $n_{k} l_{j k}+\phi \dot{n}_{k}=h,(17)$ yields $\dot{W}_{k} / W_{k}=0, \forall \alpha$.
} 
effective demand shortage coexist, thereby bringing about persistent deflation. The symmetric steady-state equilibrium with stagnation, therefore, is a double $\left(n^{*}, e^{*}\right)$ in which $\dot{r}=0, \dot{R}=0, \dot{e}=0, \dot{n}=0, \dot{q}=0, \dot{\bar{P}} / \bar{P}<0, \dot{m}>0$. The above definition means that not only real and nominal rates of interest are fixed, but also $e, n$ and $q$ remain constant. In addition, steady state with stagnation requires involuntary unemployment, such that $n^{*} l^{*}<h$, consequently causing nominal wages, nominal prices, and the price level to continue to decline, and therefore $m$ diverges infinitely. This is because, from $P_{j k} / \bar{P}_{k}=n^{-1 /(1-\sigma)} x^{-1 /(1-\sigma)},(13)$ and (17), $\dot{\bar{P}} / \bar{P}=\dot{P} / P=\dot{W} / W$ $=\alpha\left(n^{*} l^{*} / h-1\right)<0$ holds in a steady state with stagnation. ${ }^{10}$ Thus, from the above definition, $v^{\prime}(m)=\beta>0$ holds in a steady state with stagnation.

Now, we present the steady-state conditions required for this economy to be in stagnation. Since $e$ is constant, $r=\rho$ holds from (10). Then, from (19) and (14), the real value of equity is

$$
q=(1 / \rho)[1 /(\xi-1)] w h e n^{\sigma /(1-\sigma)} x^{1 /(1-\sigma)} .
$$

Here, we assume that the free entry condition (15) holds as equality, such that $\phi w=$ $q$, and therefore $\dot{n}=0$ is obtained as the corner solution in a steady state with stagnation. By introducing (20) into the equality, the free entry condition is rewritten as

$$
\phi \rho(\xi(n)-1)=h e n^{\sigma /(1-\sigma)} x^{1 /(1-\sigma)} .
$$

On the other hand, from (18), total labor demand is

$$
n l=n y=h e n^{1 /(1-\sigma)} x^{1 /(1-\sigma)} .
$$

From (17) and (22), the instant rate of nominal wage inflation is as follows:

$$
\dot{W} / W=\alpha\left(e n^{1 /(1-\sigma)} x^{1 /(1-\sigma)}-1\right) .
$$

Since $n$ is constant in a steady state, differentiating the logarithm of $P_{j k} / \bar{P}_{k}=P / \bar{P}=$ $n^{-1 /(1-\sigma)} x^{-1 /(1-\sigma)}$ and (13) with respect to time yields $\dot{\bar{P}} / \bar{P}=\dot{W} / W$. Therefore, from (23), real money balances expand at the rate of $\dot{m} / m=-\alpha\left(e n^{1 /(1-\sigma)} x^{1 /(1-\sigma)}-1\right)$ in a steady

${ }^{10}$ Lemma 1 presents the conditions required for unemployment to exist in a steady state. 
state because $\dot{m} / m=-\dot{\bar{P}} / \bar{P}$ from (16). Finally, from (10), (23) and $\dot{\bar{P}} / \bar{P}=\dot{W} / W$, Keynes's rule in steady state is rewritten as

$$
\rho+\alpha\left(e n^{1 /(1-\sigma)} x^{1 /(1-\sigma)}-1\right)=\beta e .
$$

Hence, this model yields a system of two equations: equation (21), which stems from the free entry condition, determines the equilibrium number of firms $n$ given the level of real consumption $e$; and equation (24), which stems from the Euler equation, determines real consumption given the number of firms. These two equations together determine the steady-state levels of both $n$ and $e$. Solving (21) and (24) with respect to $n$ yields

$$
\phi \rho(\xi-1) n^{*-\sigma /(1-\sigma)}\left\{\beta-\alpha n^{* 1 /(1-\sigma)} x^{1 /(1-\sigma)}\right\}=h(\rho-\alpha) x^{1 /(1-\sigma)},
$$

where $\xi \equiv \sigma-(\sigma-1)\left(1 / x n^{*}\right)$. From (25), in order for a steady-state number of firms, $n^{*}$, to exist, the following conditions must hold (see Figure 1):

$$
\phi \rho(\sigma-1)(1-1 / x)\left(\beta-\alpha x^{1 /(1-\sigma)}\right)<h(\rho-\alpha) x^{1 /(1-\sigma)} .
$$

Under the condition of (26), $n^{*}$ exists and is represented by $n^{*}=n^{*}(\alpha, \beta, \rho, x, h, \phi)$, which depends on parameters of the model

\section{Figure 1.}

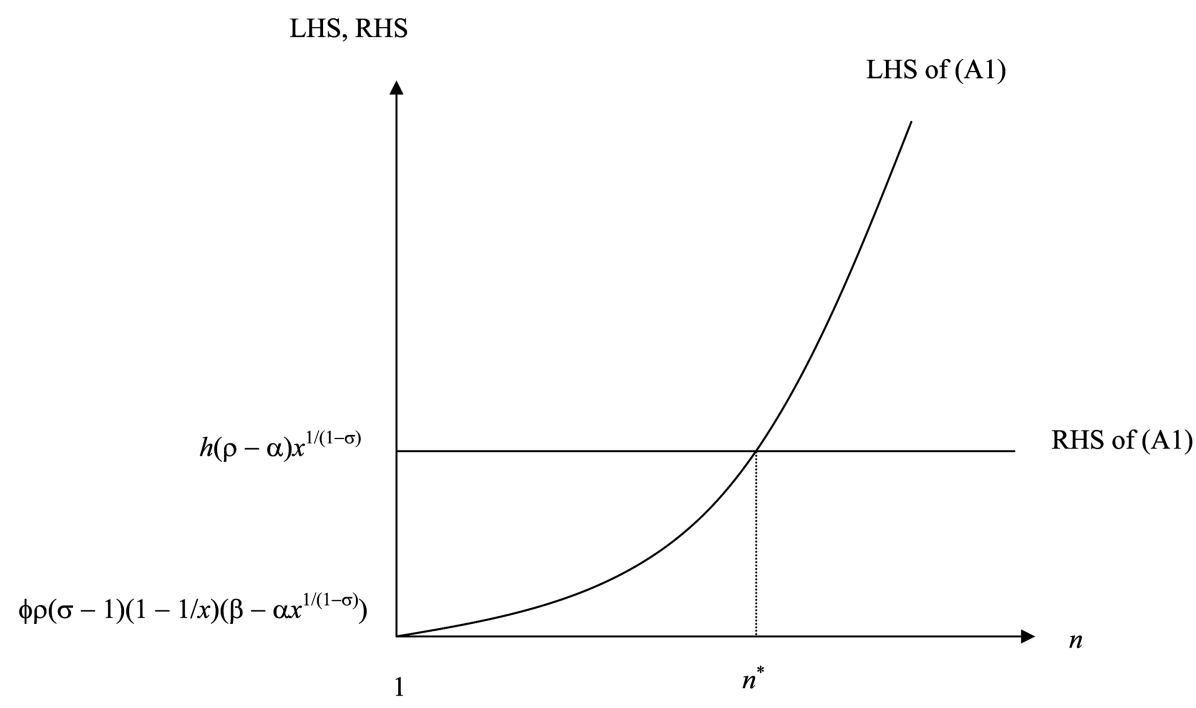




$$
\partial n^{*} / \partial \beta<0, \partial n^{*} / \partial \rho>0, \partial n^{*} / \partial x<0, \partial n^{*} / \partial h>0, \partial n^{*} / \partial \phi<0 .
$$

Next, we find the condition required for unemployment to exist in a steady state, i.e., $n^{*} l^{*}<h\left(\Leftrightarrow n^{*} l^{*} / h<1\right)$, where $n^{*} l^{*}$ is the total labor demand and $h$ is the total labor supply. From (22), in order for $n^{*} l^{*}<h$ to hold, in addition to (26), the following conditions must hold:

$$
n^{*}(\alpha, \beta, \rho, x, h, \phi)<n_{f}^{*},
$$

where $n_{f}{ }^{*} \equiv h / \phi \rho(\sigma-1)+x^{-1}$ represents the number of firms under full employment (see Appendix 2). Therefore, in order for unemployment to exist in a steady state, the steady-state number of firms must be dominated by $n_{f}^{*}$.

Finally, we find the condition required for the existence of an effective demand shortage in steady state. Under the above-defined stagnation, steady-state consumption not only must exceed zero, but must also be below the fullemployment production level. Thus, steady-state consumption must satisfy $0<e^{*}<$ $e_{f}$, where $e_{f}$ is the full-employment production level compatible with the labor market clearing condition, $n l=h$. From Appendix 2, the condition under which effective demand shortages exist is represented by the following lemma:

Lemma 1: The steady-state consumption exists if $\beta e_{f}>\rho>\alpha$ holds, where $e_{f}=$ $\left[(h / \phi \rho(\sigma-1))+x^{-1}\right]^{1 /(\sigma-1)} x^{1 /(\sigma-1)}$.

(see Appendix 3 for proof).

The condition in Lemma 1 shows that if $\alpha$ and $\phi$ are sufficiently low, and if $\beta, x$ and $h$ are sufficiently large, then a shortage of consumption occurs. ${ }^{11}$ Under the condition, the steady-state consumption, $e^{*}$, exists, and as shown in Figure 2, the equilibrium is below the amount of full employment production (i.e., $e^{*}<e_{f}$ ). Finally, the condition in Lemma 1 validates the transversality condition:

$$
\dot{m} / m=-\dot{\bar{P}} / \bar{P}=\rho-\beta e^{*}<\rho .
$$

To sum up, the parameters of this model must satisfy (26), (28) and the conditions

\footnotetext{
${ }^{11}$ It is possible to consider a neoclassical case where those parameter values admit full employment as a steady state. However, our main interest lies in the interaction between openness and effective demand under stagnation, so we have concentrated on a steady state with an effective demand shortage.
} 
Figure 2.

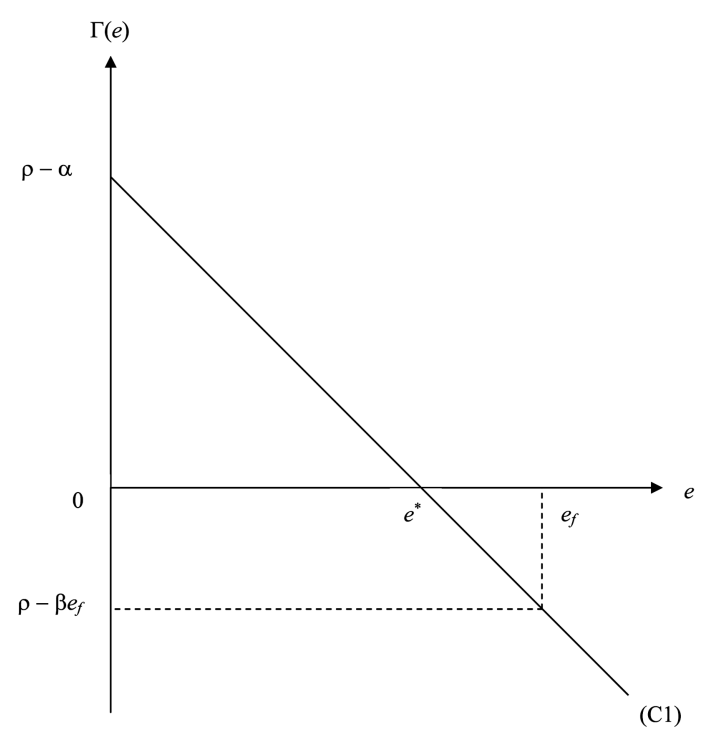

in Lemma 1 , for $n^{*}>0, n^{*} l\left(n^{*}, e^{*}\right)<h$ and $0<e^{*}<e_{f}$ to hold together in a steady state. In what follows, we assume that (26), (28) and the parametric condition in Lemma 1 are valid so that a steady state with stagnation exists in this economy.

\section{Autarky Versus Free Trade}

To examine the effect of openness on effective demand of each country under stagnation, this section, first, compares the number of firms under autarky to the number under free trade. The autarky equilibrium is obtained by setting $x=1$ in both (21) and (24). From (21), the free entry condition in autarky is rewritten as

$$
\phi \rho(\xi-1)=h e n^{\sigma /(1-\sigma)},
$$

where $\xi \equiv \sigma-(\sigma-1)(1 / n)$. From (24), Keynes's rule in autarky is

$$
\rho+\alpha\left(e n^{1 /(1-\sigma)}-1\right)=\beta e .
$$

By substituting $e$ from (30) into (29), the steady-state number of firms in autarky is derived from 


$$
\phi \rho(\xi-1)\left(\beta-\alpha n^{A(1 /(1-\sigma))}\right) n^{A(-\sigma /(1-\sigma))}=h(\rho-\alpha): \text { Autarky }
$$

where $\xi \equiv \sigma-(\sigma-1)\left(1 / n^{A}\right)$, and $n^{A}$ is the steady-state number of firms in autarky.

Next, we consider the economy in free trade where $x>1$ holds. In this case, by substituting $e$ from (24) into (21), the number of firms in free trade is derived from

$$
\phi \rho(\xi-1) n^{F(-\sigma /(1-\sigma))}\left\{\beta-\alpha n^{F(1 /(1-\sigma))} x^{1 /(1-\sigma)}\right\}=h(\rho-\alpha) x^{1 /(1-\sigma)} \text { : Free trade }
$$

where $\xi=\sigma-(\sigma-1)\left(1 / x n^{F}\right)$ and $n^{F}$ is the steady-state number of firms in free trade. Hence, by comparing (31) and (32), we obtain the following proposition:

Proposition 1: Under a steady state with stagnation, $x n^{F}>n^{A}>n^{F}$ holds.

Proof: From (31), we obtain

$$
\phi \rho\left(\xi\left(n^{A}\right)-1\right)\left(\beta-\alpha n^{A(1 /(1-\sigma))}\right) n^{A(-\sigma /(1-\sigma))}=h(\rho-\alpha) .
$$

While, from (32), we obtain

$$
\phi \rho\left(\xi\left(n^{F}\right)-1\right) x^{1 /(1-\sigma)} n^{F(-\sigma /(1-\sigma))}\left(\beta-\alpha n^{F(1 /(1-\sigma))} x^{1 /(1-\sigma)}\right)=h(\rho-\alpha) .
$$

By comparing (33) with (34), we obtain $n^{A}>n^{F}$, because $x>1$ and $d \xi(n) / d n>0$ hold. Here, let us define the global number of firms as $g^{F}=x n^{F}$. Then (34) can be written as

$$
\phi \rho\left(\xi\left(g^{F}\right)-1\right) g^{F-\sigma /(1-\sigma)}\left(\beta-\alpha g^{F 1 /(1-\sigma)}\right)=x h(\rho-\alpha)
$$

By comparing (33) with (35), we obtain $g^{F}\left(=x n^{F}\right)>n^{A}$ from $x>1$.

Proposition 1 shows that a move from autarky to free trade leads to the exit of domestic firms, so that $n^{A}>n^{F}$. However, domestic households gain access to foreign goods, with $g^{F}\left(=x n^{F}\right)>n^{A}$.

Next, we compare the consumption level of autarky with that of free trade. From (24), the steady-state consumption under autarky is derived by setting $x=1$ to (24) as

$$
\rho+\alpha\left(e^{A} n^{A 1 /(1-\sigma)}-1\right)=\beta e^{A}: \text { Autarky }
$$


where $e^{A}$ is the steady-state consumption under autarky. The steady-state consumption under free trade is derived from

$$
\rho+\alpha\left(e^{F} g^{F 1 /(1-\sigma)}-1\right)=\beta e^{F}: \text { Free trade }
$$

where $e^{F}$ is the steady-state consumption under free trade. Since $g^{F}\left(=x n^{F}\right)>n^{A}$ holds, a comparison of (36) and (37) yields the following relationship:

$$
e^{F}<e^{A}
$$

Hence, we obtain the following proposition:

Proposition 2: The level of effective demand in autarky is larger than in free trade under a steady state with stagnation.

The above proposition is explained intuitively as follows. The regime shift from autarky to free trade increases the value of the consumption index by expanding the range of consumption goods available to people in every country. This implies that people can enjoy higher utility without increasing expenditure for consumption. However, under a steady state with stagnation, where expenditure for consumption has reached an upper bound, the rise in efficiency of consumption utility lowers the time preference rate of Keynes's rule through a decline in the inflation rate, while not affecting the liquidity premium that represents the desire to hold money. Therefore, openness causes realized consumption to decrease and saving to increase in all countries. Consequently, effective demand decreases.

We can give another intuition for Proposition 2 by considering the consumption index with a final goods production function where inputs are intermediate goods. ${ }^{12}$ Given a persistent consumption shortage, an expansion in the range of intermediate inputs from free trade enables final goods firms to produce more output without increasing intermediate inputs. However, under stagnation, where demand for final goods has reached an upper bound, the rise in productivity of production technology makes final goods firms realize they are producing more than the realized final goods demand. Therefore final goods producers have to

${ }^{12}$ If we consider the consumption index represented by (4) along with a final goods production function where the input is intermediate goods, the index level can be taken as the productivity of production technology. 
decrease their demand for intermediate goods, and hence, employment required by the intermediate sector falls. Decreases in employment then lead to a decrease in the rate of time preference through a rise in the deflation rate (the left hand side of (24) falls), and thereby decrease the desire for consumption, consequently cutting effective demand.

\section{Conclusions}

Neoclassical international economics has devoted enormous energy to the question of whether openness increases economic welfare. However, most models of international economics are based on the assumption of full employment. By contrast, this paper has provided a characterization of the role of trade in the determination of effective demand under stagnation. The main result is as follows. The regime shift from autarky to free trade expands the range of consumption goods available to people in every country and thereby increases the value of people's consumption utility function. However, under stagnation, where expenditure for consumption has reached an upper bound, the rise in efficiency of consumption utility lowers the time preference rate of Keynes's rule through a decline in the inflation rate, while not affecting the liquidity premium that represents the desire to hold money. Therefore, openness causes realized consumption to decrease and saving to increase in all countries. Consequently, effective demand decreases and stagnation worsens.

The results of this model are consistent with the impact of the free trade agreement (FTA) between Japan and Singapore which went into effect in 2002. Indeed, the unemployment rate in Japan was 5.0 per cent in 2001 but it rose to 5.4 per cent in 2002, while the unemployment rate in Singapore was 2.8 per cent in 2001 but it rose to 4.3 per cent in $2002 .{ }^{13}$ Thus, the result of proposition 2 is supported with the empirical data, because, in both Japan and Singapore, the unemployment rates rose contemporaneously after the FTA between Japan and Singapore.

\section{Acknowledgements}

The author is grateful to an anonymous referee for helpful comments, which have substantially improved the paper. This research was supported by Grants-in-

\footnotetext{
${ }^{13}$ See IMF (2003)
} 
Aid for Scientific Research from the Ministry of Education and Tezukayama University.

Received 2 March 2007, Accepted 29 October 2007

\section{Appendix 1}

We shall find the condition for the existence of a steady-state number of firms. From (25), we obtain

$$
\phi \rho(\xi-1) n^{* \sigma /(\sigma-1)}\left(\beta-\alpha n^{* 1 /(1-\sigma)} x^{1 /(1-\sigma)}\right)=h(\rho-\alpha) x^{1 /(1-\sigma)},
$$

where $\xi \equiv \sigma-(\sigma-1)\left(1 / x n^{*}\right)$. When $n^{*}=1$, (A1) can be rewritten as

$$
\phi \rho(\sigma-1)(1-1 / x)\left(\beta-\alpha x^{1 /(1-\sigma)}\right)=h(\rho-\alpha) x^{1 /(1-\sigma)} .
$$

Hence, if $\phi \rho(\sigma-1)(1-1 / x)\left(\beta-\alpha x^{1 /(1-\sigma)}\right)<h(\rho-\alpha) x^{1 /(1-\sigma)}$ holds, the steady-state number of firms exists and is represented by $n^{*}=n^{*}(\alpha, \beta, \rho, x, h, \phi)$ (see Figure 1).

\section{Appendix 2}

In this appendix, we derive steady-state consumption and the number of firms under full employment, which are defined as $e_{f}^{*}$ and $n_{f}{ }^{*}$, respectively. When full employment holds, the labor market clearing condition $n l=h$ can be rewritten as $e_{f}$ $=n_{f}^{1 /(\sigma-1)} x^{1 /(\sigma-1)}$. Substituting this condition into (21) yields the steady-state number of firms as $n_{f}^{*}=(h / \phi \rho(\sigma-1))+x^{-1}$. By substituting $n_{f}^{*}$ into the above labor market clearing condition, we then obtain the steady-state consumption under full employment as

$$
e_{f}^{*}=\left[(h / \phi \rho(\sigma-1))+x^{-1}\right]^{1 /(\sigma-1)} x^{1 /(\sigma-1)} .
$$

From (B1), we obtain the following properties:

$$
\partial e_{f}^{*} / \partial x>0, \partial e_{f}^{*} / \partial h>0, \partial e_{f}^{*} / \partial \phi>0, \partial e_{f}^{*} / \partial \rho<0 .
$$




\section{Appendix 3}

In this appendix, we find conditions required for steady-state consumption to exist under stagnation. If the economy falls into a state of stagnation in which there are effective demand shortages and deflation, then steady-state consumption values must satisfy $0<e^{*}<e_{f}$, where $e_{f}\left(\equiv\left[(h / \phi \rho(\sigma-1))+x^{-1}\right]^{1 /(\sigma-1)} x^{1 /(\sigma-1)}\right)$ is the fullemployment production level from Appendix 2. Under conditions (26) and (28) by which $n^{*}=n^{*}(\alpha, \beta, \rho, x, h, \phi)$ exists, (24) can be rewritten as

$$
\Gamma(e)=\rho+\alpha\left(e n^{*}(\alpha, \beta, \rho, x, h, \phi)^{(1 /(1-\sigma))} x^{1 /(1-\sigma)}-1\right)-\beta e .
$$

From $(\mathrm{C} 1)$, if $\Gamma(0)=\rho-\alpha>0$ and $\Gamma\left(e_{f}\right)=\rho-\beta e_{f}<0$ hold, a steady-state consump-tion exists, as depicted in Figure 2. These conditions can be summarized as follows:

$$
\beta e_{f}>\rho>\alpha \text {. }
$$

(C2) is equivalent to the condition in Lemma 1.

\section{References}

Baldwin R, Forslid R. (1999) 'Incremental trade policy and endogenous growth: a $q$ theory approach'. Journal of Economic Dynamics and Control, 23, 797-822.

Baldwin R, Forslid R. (2000) 'Trade liberalization and endogenous growth: a $q$-theory approach'. Journal of International Economics, 50, 497-517.

Grossman G, Helpman E. (1991) Innovation and growth in global economy. MIT Press: Cambridge.

Grossman G, Helpman E. (1995) Technology and trade. In: Grossman G, Rogoff K (Eds), Handbook of international economics, vol.3. Elsevier Science: Amsterdam, p. 12791337.

IMF (2003) International Financial Statistics LVI.

Johdo, W. (2002) 'R\&D investment and effective demand.' The Economic Review (The Institute of Economic Research, Hitotsubashi University) 53, 79-85.

Lee H, Ricci L, Rigobon R. (2004) 'Once again, is openness good for growth?' Journal of Development Economics, 75, 451-472.

Matsuzaki, D. (2003) 'The effects of a consumption tax on effective demand under stagnation.' Japanese Economic Review, 54, 101-118.

Ono Y. (2001) 'A reinterpretation of chapter 17 of Keynes's general theory: Effective demand shortage under dynamic optimization'. International Economic Review, 42, 207-236. 
Ono Y, Ogawa K, Yoshida A. (2004) 'Liquidity trap and persistent unemployment with dynamic optimizing agents: Empirical evidence'. Japanese Economic Review, 55, 355-371.

Ono, Y. (2006) 'International asymmetry in business activity and appreciation of a stagnant country's currency'. Japanese Economic Review, 57, 101-120.

Peretto P. (2003) 'Endogenous market structure and the growth and welfare effects of economic integration'. Journal of International Economics, 60, 177-201.

Rivera-Batiz L, Romer P. (1991a) 'Economic integration and endogenous growth'. Quarterly Journal of Economics, 106, 531-555.

Rivera-Batiz L, Romer P. (1991b) 'International trade with endogenous technological change'. European Economic Review, 35, 715-721. 